\title{
Characterization of Sintered Ceramic Tiles Produced from Steel Slag
}

\author{
Benneth C. Chukwudi ${ }^{1 *}$, Patrick O. Ademusuru ${ }^{1}$, Boniface A. Okorie ${ }^{2}$ \\ ${ }^{1}$ Department of Mechanical Engineering, Imo State University, Owerri, Nigeria \\ ${ }^{2}$ Department of Materials and Metallurgical Engineering, Enugu State University of Science and Technology, Enugu, Nigeria \\ Email: "benkeke07@yahoo.com
}

Received March 15, 2012; revised April 21, 2012; accepted May 7, 2012

\begin{abstract}
Ceramic tiles were processed in this present work using clay mineral and steel slag. Steel slag in the range of 0 - 100 wt\% was added to kaolinite clay. The blended samples were hydraulic pressed into rectangular moulds, oven dried and sintered to $1200^{\circ} \mathrm{C}$. Linear shrinkage, apparent porosity, water absorption, bulk density, and modulus of rupture of sintered specimens were examined. Phases present in the sintered products were identified using X-ray Diffractometer (XRD), while the microstructural examination was conducted using Scanning Electron Microscopy (SEM). The elements present in the sintered products were identified using Energy Dispersive X-ray (EDX). Phases like quartz, wollastonite, anorthite and enstatite were identified in the sintered products. The SEM revealed crystals embedded in the glassy matrix. EDX studies detected Aluminum (Al), Silicon (Si), Magnesium (Mg) and Calcium (Ca) as the major metal ions. Results obtained showed that samples containing 20 - $60 \mathrm{wt} \%$ steel slag have very good usable ceramic tile properties.
\end{abstract}

Keywords: Sintering; Phases; Pig Iron; Mineral

\section{Introduction}

Slag is a major by-product in the iron and steel making industry [1]. It may be classified into two main categories namely-blast furnace slag and steel slag. Blast furnace slag is produced during pig iron production in the blast furnace, while steel slag is generated at the steel melting shop during steel manufacturing. It is well known that removal of excess silicon and carbon from iron is necessary in order to produce steel. This is achieved through oxidation by adding limestone and coke [2].

Steel slag has higher amount of iron and its physical characteristics are similar to air-cooled iron slag. Iron content of steel slag is the major difference between blast furnace slag and steel slag. Slag, 2009 reported that the iron content of blast furnace slag is about $0.5 \%$ against $10 \%-23 \%$ for steel slag. Emery, 2004 observed that blast furnace utilization in many industrial applications is well known compared to steel slag. Furthermore, the practice of incorporating industrial waste in tile production is gaining ground in many ceramic industries all over the world. Consequently, several studies have been carried out on the production of ceramic products using both organic and inorganic waste like sewage sludge,

"Corresponding author. natural stone waste, fly ashes, and metallurgical waste [3]. The need to characterize ceramic bodies from such combinations is not only justified, but imperative. This study is a contribution in that regard.

\section{Experimental Procedure}

Steel slag used in this work was collected from Delta Steel Company, Ovwian Aladja, Delta State. Kaolinite sample was collected from Agbaghara Nsu in Ehime Mbano Local Government Area of Imo State. Both samples were separately crushed, ground and sieved using ASTM sieve to obtain 100\% passing 200 mesh. The aggregates obtained from sieving were batched and blended in the range of $0-100 \mathrm{wt} \%$. Water was added to temper and the mixture thoroughly worked into a paste. The paste was introduced into fabricated mild steel mould measuring approximately $90 \mathrm{~mm} \times 70 \mathrm{~mm} \times 10 \mathrm{~mm}$. The required quantity of batch mixture (paste) was introduced into the fabricated metal mould and pressed under a pressure of $40 \mathrm{MPa}$ using hydraulic pressing machine. The formed products were allowed to air dry for two days, followed by oven drying for 1 hour at $105^{\circ} \mathrm{C}$. It was then sintered to $1200^{\circ} \mathrm{C}$, with 30 minutes soaking time, using GK4 $1300^{\circ} \mathrm{C}$ Electric Furnace. Then the sintered products were furnace-cooled to ambient conditions. Standard methods were applied to determine the linear shrinkage 
and modulus of rupture of sintered products. Apparent porosity, bulk density, and water absorption of the sintered products were determined following ASTM C 373 standard procedure. Phases present in the sintered specimens were identified using X-ray Diffractormeter (XRD), while the microstructural examination was conducted using Scanning Electron Microscopy (SEM). The elements present in the sintered products were identified using Energy Dispersive X-ray (EDX).

\section{Results and Discussion}

\subsection{Linear Shrinkage}

The average total (drying and sintered shrinkage) values are presented in Table 1 It is shown that the highest shrinkage of $19.28 \%$ was obtained for sample (tile 1) sintered to $1200^{\circ} \mathrm{C}$, followed by $9.09 \%$ recorded by tile 2 . This shows that steel slag gave some level of dimensional stability to the tiles since tile 1 without steel slag recorded very high shrinkage values compared to tiles with steel slag compositions. In the production of standard size ceramic tiles, it is not desired to have a high firing shrinkage.

Figure 1 shows that the values of firing shrinkage decreased with increase in steel slag addition. Apart from tile 1, linear shrinkage of the tested tiles, compared well with values recorded by [4]. Generally, firing shrinkage values increased with higher sintering temperatures due to the densification of samples as a result of sintering. Again, linear shrinkage affects porosity as higher shrinkage resulted to the closure of pores thus leading to reduction in porosity.

Table 1. Results of tested parameters.

\begin{tabular}{cccccc}
\hline \multirow{2}{*}{ Description } & \multicolumn{5}{c}{ Sintered at 1200 C } \\
\cline { 2 - 6 } & Tile 1 & Tile 2 & Tile 3 & Tile 4 & Tile 5 \\
\hline Apparent porosity, AP (\%) & 31.32 & 15.38 & 11.29 & 14.06 & 14.24 \\
Water absorption, WA (\%) & 17.12 & 7.66 & 5.61 & 6.97 & 7.04 \\
Linear shrinkage (LS) & 19.28 & 9.09 & 8.18 & 7.55 & 6.36 \\
Bulk density, BD (g/cm $\left.{ }^{3}\right)$ & 1.82 & 2.01 & 2.01 & 2.01 & 2.00 \\
MOR (MPa) & 2 & 25 & 38 & 55 & 58 \\
\hline
\end{tabular}

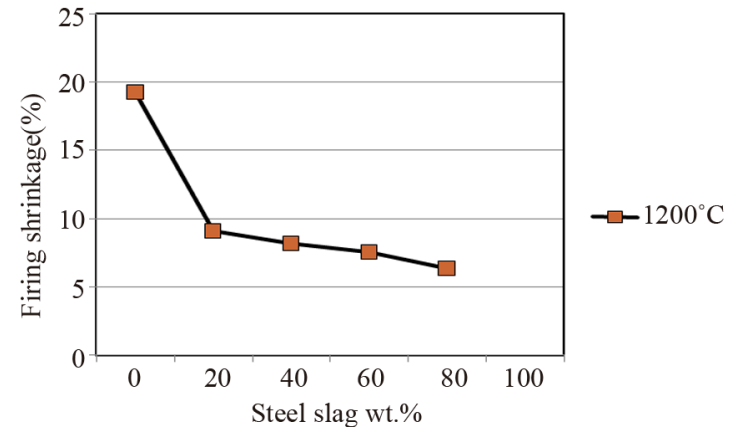

Figure 1. Firing shrinkage against steel slag addition at $\left(1200^{\circ} \mathrm{C}\right)$ sintering temperature.

\subsection{Apparent Porosity and Bulk Density}

Results obtained are shown in Table 1 and Figure 2. Tile 1 sintered to $1200^{\circ} \mathrm{C}$ with the highest porosity of $31.32 \%$ also recorded the lowest bulk density of $1.82 \mathrm{~g} / \mathrm{cm}^{3}$. Tile 3 sintered to $1200^{\circ} \mathrm{C}$ with the lowest porosity of $11.29 \%$ recorded the highest bulk density of $2.01 \mathrm{~g} / \mathrm{cm}^{3}$. Similar observations were observed for other samples though the bulk densities seem to remain constant as porosity increased. This is in agreement with the fact that densification reduces pore spaces and hence volume upon which density depends.

\subsection{Water Absorption}

Water absorption is commonly referred to as an indicator of porosity value of wall and floor tiles. Table 1 shows the results obtained. Tile 1 sintered to $1200^{\circ} \mathrm{C}$ with the highest water absorption of $17.12 \%$ also recorded the highest porosity of $31.32 \%$. Tile 3 sintered to $1200^{\circ} \mathrm{C}$ with the lowest water absorption of 5.61\% also recorded the lowest porosity of $11.29 \%$. Therefore, it can be said that water absorption directly varies with apparent porosity; hence both properties showed similar trend in the overall steel slag additions. Figure 3 shows that water absorption of samples sintered to $1200^{\circ} \mathrm{C}$ decreased with increasing steel slag addition down to $40 \mathrm{wt} \%$ before slightly increasing with further additions. Romero et al., 2008, suggested that closed porosity dominates at high

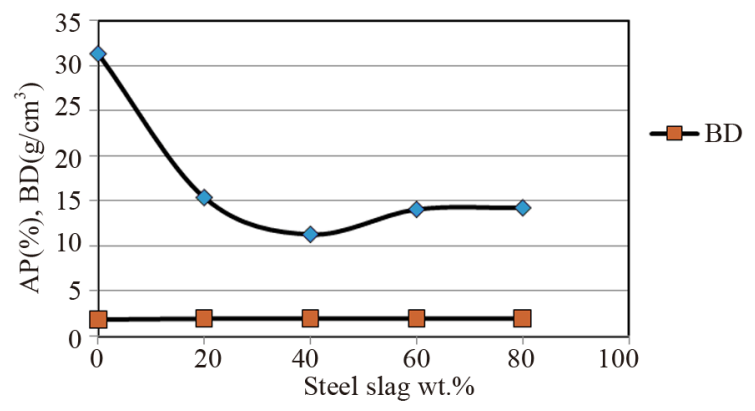

Figure 2. Apparent porosity (AP) and bulk density (BD) against steel slag addition $\left(1200^{\circ} \mathrm{C}\right)$.

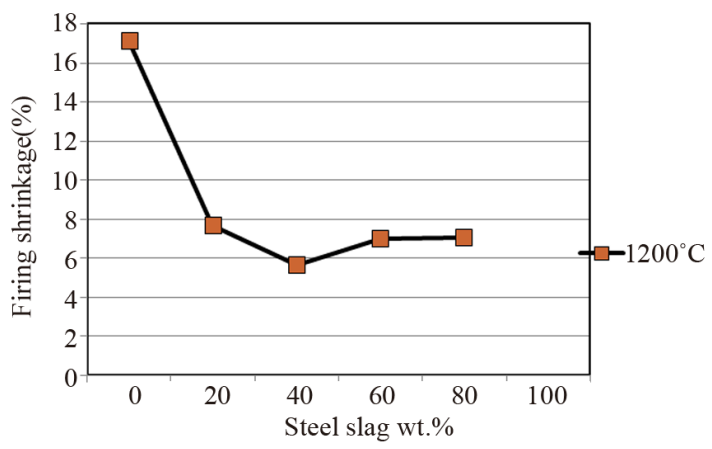

Figure 3. Water absorption against steel slag addition sintering temperature $\left(1200^{\circ} \mathrm{C}\right)$. 
temperatures hence justifying apparent porosity values recorded in this work. Apart from tile 1, water absorption values recorded by other tiles compared well with values recommended by EN 14411 [5], which stipulated 10\% to $18 \%$ and $6 \%$ to $10 \%$ for wall tiles and floor tiles respectively. Water absorption requirements for floor tiles are much lower; therefore samples generated from this work could be suitable for floor tiles purposes.

\subsection{Modulus of Rupture (MOR) Result}

MOR is the measurement of the transverse strength of tile. The higher the value, the stronger the tile. The results obtained are shown in Table 1 and Figure 4. It shows that the addition of steel slag drastically increases the strength of tiles. MOR of normal floor tiles varies from $20 \mathrm{MPa}$ to $35 \mathrm{MPa}$ [5].

\subsection{XRD Result}

XRD results of sintered samples are shown in Figures 5-8. Results of all the tested sintered products (tiles 2 - 5) indicated the presence of quartz $\left(\mathrm{SiO}_{2}\right)$ as expected. From the XRD images, quartz particles have diffraction peaks at $4.24,2.45,2.23,2.12$ and 1.37 as observed by [6], 2010). XRD pattern of (tiles 2 - 5) also showed the

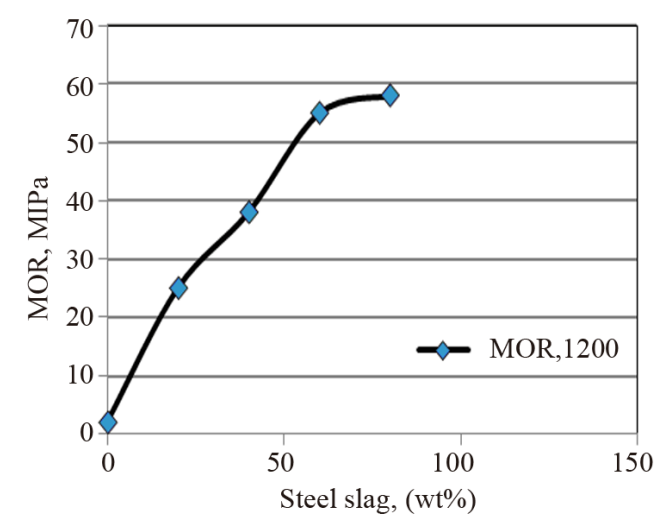

Figure 4. Modulus of rupture against steel slag addition.

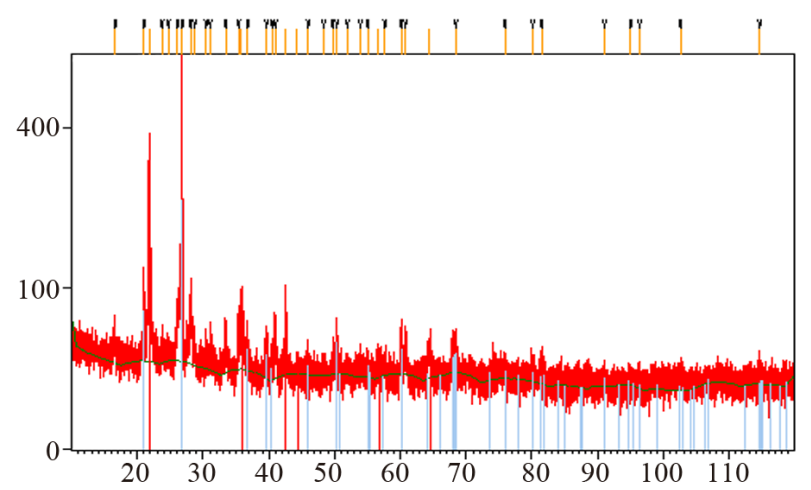

Figure 5. XRD patterns (intensity (cps) vs. degrees $2 \Theta$ ) for the tile 2 sintered to $1200^{\circ} \mathrm{C}$.

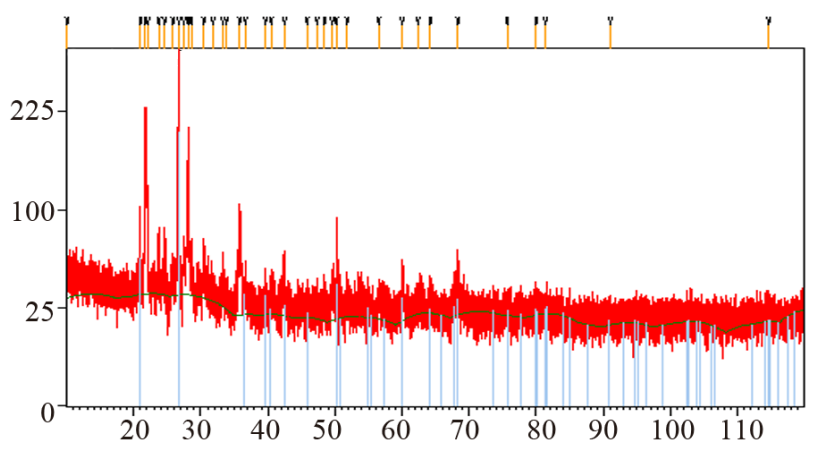

Figure 6. XRD patterns (intensity (cps) vs. degrees $2 \Theta$ ) for the tile 3 sintered to $1200^{\circ} \mathrm{C}$.

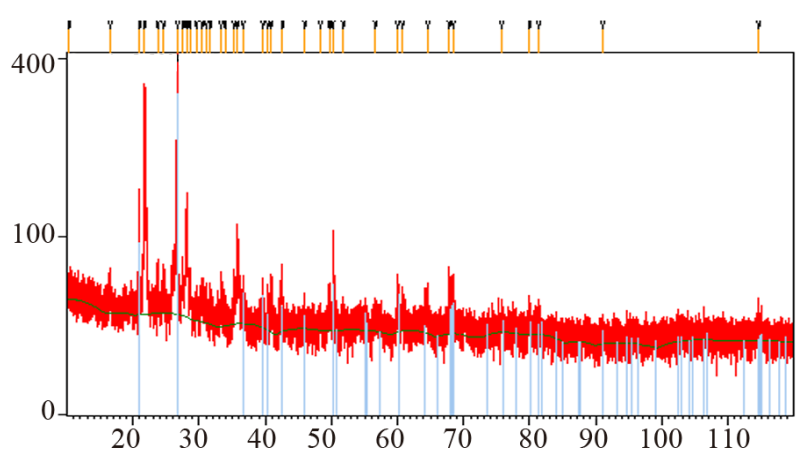

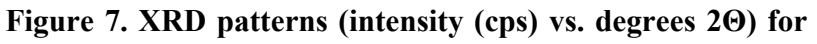
the tile 4 Sintered to $1200^{\circ} \mathrm{C}$.

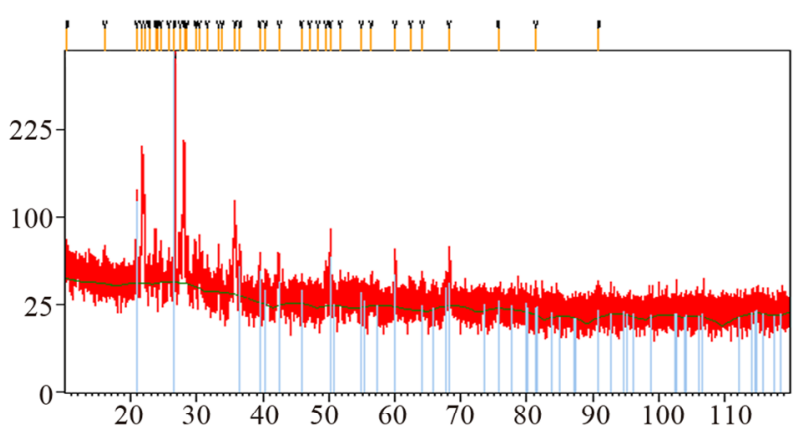

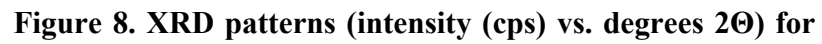
the tile 5 sintered to $1200^{\circ} \mathrm{C}$.

presence of enstatite $\left(\mathrm{MgOSiO}_{2}\right)$. The $\mathrm{XRD}$ images showed that enstatite particles have diffraction peaks at 3.17, 2.54, and 1.48 as indicated by Mineral Data, 2001. The formation of enstatite phase may be attributed to the increasing amount of $\mathrm{MgO}$ in the ceramic tile body [7]. The presence of Anorthite $\left(\mathrm{CaO} \cdot \mathrm{Al}_{2} \mathrm{O}_{3} \cdot 2 \mathrm{SiO}_{2}\right)$ and Wollastonite $\left(\mathrm{CaOSiO}_{2}\right)$ phases were detected in (tiles 3 5). From the XRD images, anorthite particles have diffraction peaks at 4.07, 3.67, 3.62, 3.60, 3.18, and 3.12; while wollastonite particles have diffraction peaks at 3.32, 1.98, 1.97, 1.87, 1.83, 1.75, 1.53 and 1.45 as indicated by $[6,8,9]$. The presence of anorthite and wollastonite is supported by the increasing amount of Calcium Ox- 
ide $(\mathrm{CaO})$ in tiles 3 - 5, as high $\mathrm{CaO}$ content favours the formation of both phases [7]. Wollastonite crystallisation gives high mechanical resistance to tile products and a high content of this phase in a sintered body will imply higher strength of the final product [10]. This justifies the MOR values recorded by tiles 3 - 5 .

\subsection{SEM Result}

The SEM results are shown in Figures 9-12. Results showed the presence of fine grained microstructure along with relatively small pores originating most likely from the removal of volatile compounds. Tiles 2 - 5 show the presence of vitreous (glassy) phases which are evident in several zones where the microstructures are not perfectly

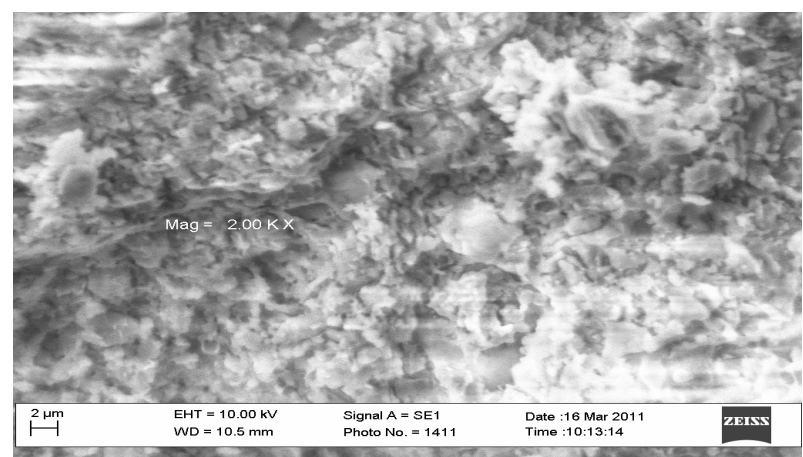

Figure 9. SEM image of tile 2 sintered to $1200^{\circ} \mathrm{C}$.

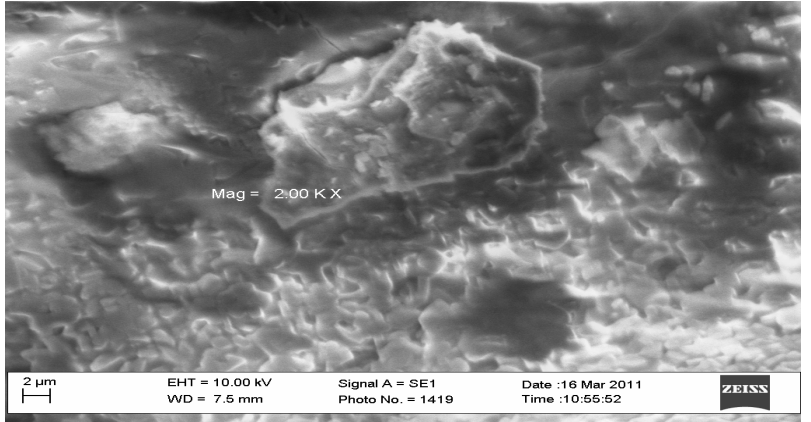

Figure 11. SEM image of tile 4 sintered to $1200^{\circ} \mathrm{C}$. visible However, some elongated grains could be seen in tiles 3 - 4, which may be responsible for the good strength of the tiles. The presence of pores (dark holes) was also indicated. Images from SEM revealed that at $1200^{\circ} \mathrm{C}$, considerable degree of vitrification took place as evidenced by the formation of glassy phases embedded in the small crystals.

\subsection{EDS Result}

The EDX results are shown in Figures 13-16. The results show that Aluminium (Al), Silicon (Si), Magnesium (Mg) and Calcium $(\mathrm{Ca})$ were detected as the major metal ions. Other elements detected include Potassium (K), Iron (Fe), Titanium (Ti) etc.

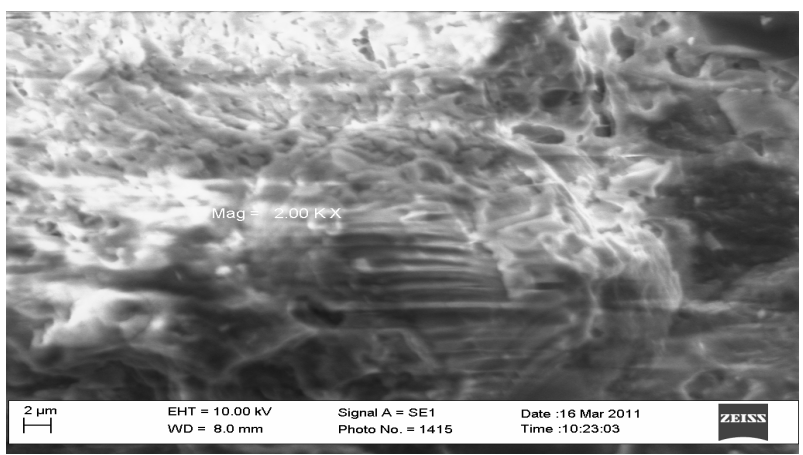

Figure 10. SEM image of tile 3 sintered to $1200^{\circ} \mathrm{C}$.

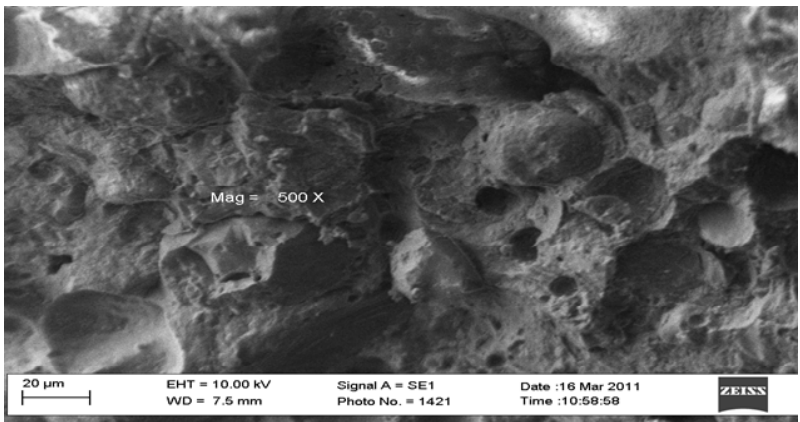

Figure 12. SEM image of tile 5 sintered to $1200^{\circ} \mathrm{C}$.

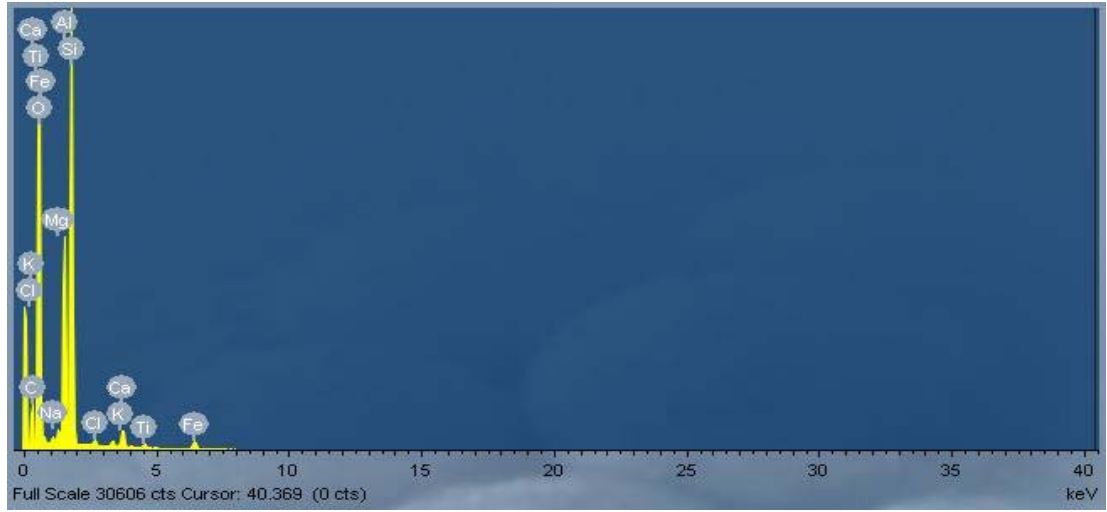

Figure 13. EDS result of tile 2 sintered to $1200^{\circ} \mathrm{C}$. 


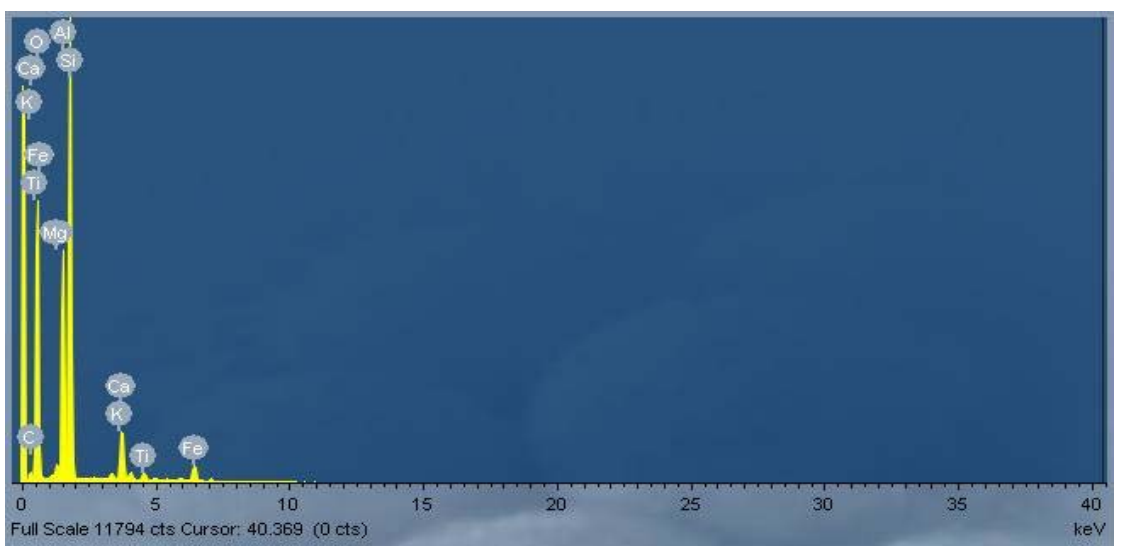

Figure 14. EDS result of tile 3 sintered to $1200^{\circ} \mathrm{C}$.

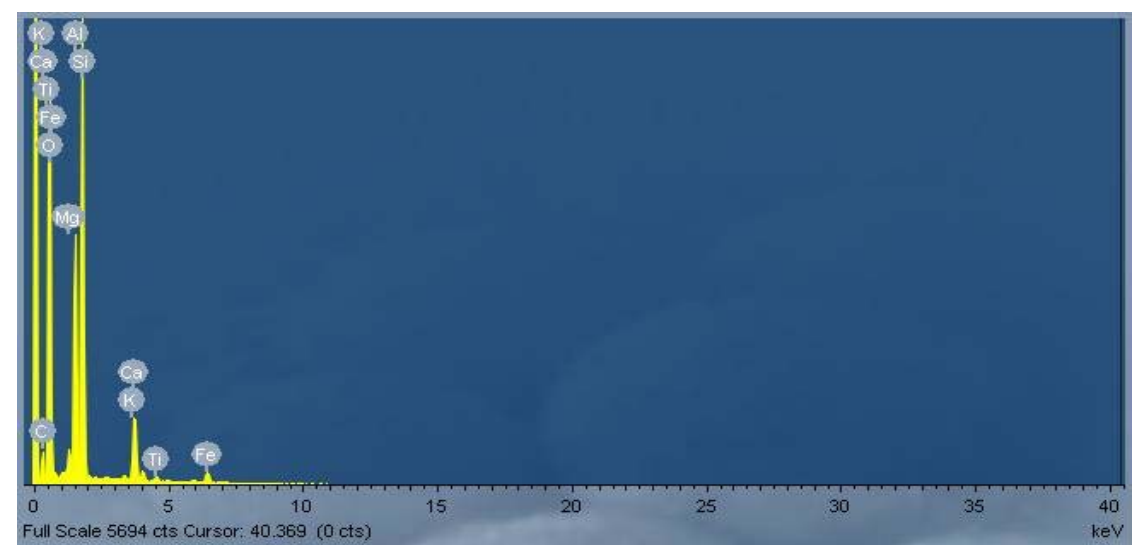

Figure 15. EDS result of tile 4 sintered to $1200^{\circ} \mathrm{C}$.

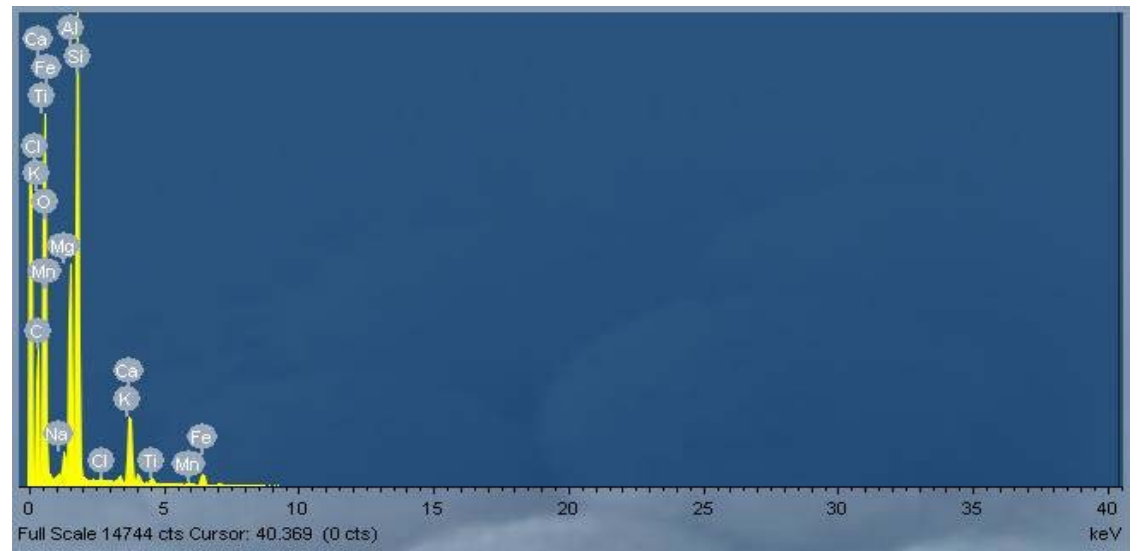

Figure 16. EDS result of tile 5 sintered to $1200^{\circ} \mathrm{C}$.

\section{Conclusion}

The production of ceramic tiles using kaolinite clay and steel slag has been investigated in this present work. The results obtained indicated the formation of phases like quartz, wollastonite, enstatite, anorthite which is very useful in the formation of high quality ceramic tile products. However, physical, service and mechanical properties tested confirmed that samples developed in this study, possessed qualities that are good for use as floor tiles.

\section{REFERENCES}

[1] I. A. Al-Negheimish, F. H. Al-Sugairand and R. Z. AlZaid, "Utilization of Local Steelmaking Slag in Concrete," Journal of King Saud University, Engineering Science, Vol. 9, No. 1, 1997, pp. 39-55.

[2] Indian Bureau of Mines, "Slag-Iron and Steel,” In: In- 
dian Minerals Yearbook, IBM Press, Nagpur, 2011, 6 p.

[3] M. Romero, A. Andres, R. Alonso, J. Virgin and J. M. Rincon, "Sintering Behaviour of Ceramic Bodies from Contaminated Marine Sediments," Ceramics International, Vol. 34, No. 8, 2008, pp. 1917-1924. doi:10.1016/j.ceramint.2007.07.002

[4] I. Ozdemir and S. Yilmaz, "Processing of Unglazed Ceramic Tiles from Blast Furnace Slag,” Journal of Materials Processing Technology, Vol. 183, No. 1, 2007, pp. 13-17. doi:10.1016/j.jmatprotec.2006.09.002

[5] EN (European Nations) 14411, "Ceramic Tiles, Definitions, Classification, Characteristics and Making,” 2004.
[6] Y. Lei, Q. X. Yan, S. P. Liu and J. Z. Yuan, "Papermaking of Mineral Fiber Composite,” Journal of Scientific \& Industrial Research, 2010, pp. 215-220.

[7] M. S. Hernandez, M. Romero and J. M. Rincon, "Nucleation and Crystal Growth of Glasses Produced by a Generic Plasma Arc-Process," Journal of the European Ceramic Society, Vol. 26, No. 9, 2005, pp. 1-10.

[8] Mineral Data Publishing, Enstatite, Version 1.2, 2001.

[9] Mineral Data Publishing, Anorthite, Version 1.2, 2001.

[10] ESMA, European Specialty Minerals Association, (IMAEurope), “Wollastonite,” 2010, pp. 1-2. 